\title{
Management of close margins in invasive breast cancer
}

\author{
R. J. Bleicher, M. Morrow \\ Department of Surgical Oncology, Fox Chase Cancer Center, Philadelphia, PA, USA.
}

\begin{abstract}
Since clinical trials have demonstrated that breast conservation is safe and effective for treatment of invasive breast cancer, there has been considerable disagreement and controversy about what constitutes an acceptable margin in breast cancer. Dogmatic adherence to a set margin for all patients may cause a higher mastectomy rate than necessary, and thus it is important to understand how various clinical and pathologic factors affect local recurrence and outcome. This review discusses that controversy, as well as what factors should be considered when evaluating patients on an individual basis.
\end{abstract}

Keywords: Breast neoplasms; Breast/pathology; Carcinoma, ductal, breast/pathology/radiotherapy/surgery; Carcinoma, lobular/pathology/radiotherapy/surgery; Chemotherapy, adjuvant; Cohort studies; Combined modality therapy; Disease-free survival; Female; Follow-up studies; Humans; Mastectomy, segmental; Neoplasm recurrence, local; Radiotherapy, adjuvant; Reoperation; Risk factors; Treatment failure

\section{Introduction}

The debate over the appropriateness of breastconserving therapy (BCT) as a management strategy for stage I and II breast cancer has been resolved by prospective randomized trials which have demonstrated survival rates equal to those seen with mastectomy [1-7]. However, the definition of a clear margin used in these trials varied from no tumor cells in direct contact with the inked specimen edge [6-8], to several centimeters of normal breast tissue $[2,3]$, leading to ongoing debate over what constitutes an adequate margin of excision. As a result, practice patterns in the United States and Europe are widely varied (Fig. 1) [9].

While there is agreement that positive margins, defined as tumor touching an inked surface, are

Correspondence to: Richard J. Bleicher, MD, Associate Member, Department of Surgical Oncology, Fox Chase Cancer Center, 333 Cottman Avenue, Philadelphia, PA 19111 USA. E-mail: richard.bleicher@fccc.edu; Tel: +215 728 2596; Fax: +215 7282773

Received 06/12/2006

Accepted 07/02/2007

BCO/548/2006/FO associated with an increased risk of local recurrence, the significance of close margins, usually defined as less than 1 or $2 \mathrm{~mm}$, is less clear. Smitt et al. reported 10-year actuarial rates of local failure of $3 \%$ for patients with negative margins compared with $16 \%$ for those with close margins [10]. In contrast, 10-year actuarial rates of local recurrence were $2 \%$ for patients with both close and negative margins in a study by Obedian and Haffty [11]. Further complicating the debate is the fact that multiple factors other than margin width influence the risk of local recurrence, making it unlikely that a margin width considered optimal for all patients can be defined. Local recurrence data from both prospective and retrospective studies is summarized in Table 1. From a practical point of view, the appropriate definition of a negative margin is one in which the residual breast tumor burden has been lowered enough by excision that it is likely to be controlled by adjuvant radiotherapy. This does not mean, however, that there are no additional tumor foci present within the breast. This article will review factors that we consider when assessing the adequacy of a surgical excision. 


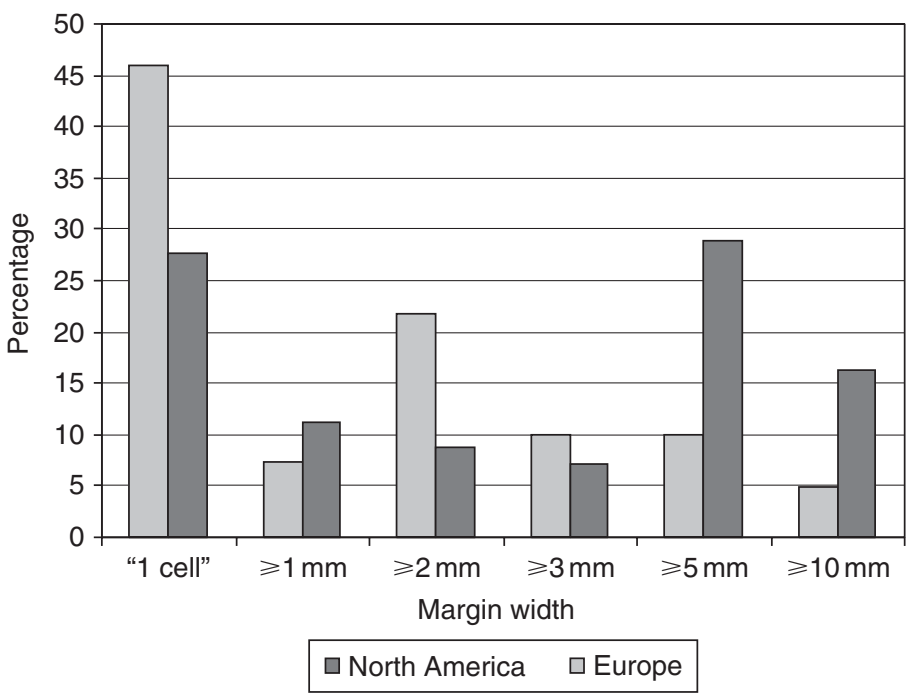

Figure 1.

Lack of consensus on the definition of margin adequacy based upon width as defined by individuals in North America and Europe [9].

Table 1. Major randomized and retrospective studies listing local recurrence rates for breast conservation with attention to margin status.

\begin{tabular}{|c|c|c|c|c|}
\hline Trial & Follow-up (years) & \% LR: BCT & $\%$ LR: Mastectomy & Margin definitions \\
\hline Institut Gustave-Roussy [3] & 15 & Neg: 9 & 14 & Neg: $\geqslant 20 \mathrm{~mm}$ \\
\hline Milan I [2] & 20 & Neg: 9 & 2 & Neg: $\geqslant 15 \mathrm{~mm}$ \\
\hline NSABP B-06 [26] & 20 & Neg: 14 & 10 & Neg: No tumor at inked margins \\
\hline $\mathrm{NCl}[4]$ & 18 & 26 & 7 & Negative margins not required \\
\hline EORTC 10801 [5] & 10 & 20 & 12 & Negative margins not required \\
\hline Danish Cooperative Group [6] & 6 & Neg: 3 & 4 & Neg: No tumor at inked margins \\
\hline Guy's Hospital [7] & 25 & 50 & 26 & Neg: No tumor at inked margins \\
\hline Freedman et al. [27] & 10 & $\begin{array}{l}\text { Close: } 14 \\
\text { Neg: } 7\end{array}$ & $\mathrm{~N} / \mathrm{A}$ & $\begin{array}{l}\text { Close: } \leqslant 2 \mathrm{~mm} \\
\text { Neg: }>2 \mathrm{~mm}\end{array}$ \\
\hline Smitt et al. [19] & 6 & $\begin{array}{l}\text { Close: } 22 \\
\text { Neg: } 3\end{array}$ & $\mathrm{~N} / \mathrm{A}$ & $\begin{array}{l}\text { Close: } \leqslant 2 \mathrm{~mm} \\
\text { Neg: }>2 \mathrm{~mm}\end{array}$ \\
\hline Park et al. [28] & 8 & $\begin{array}{l}\text { Close: } 7 \\
\text { Neg: } 7\end{array}$ & $\mathrm{~N} / \mathrm{A}$ & $\begin{array}{l}\text { Close: } \leqslant 1 \mathrm{~mm} \\
\text { Neg: }>1 \mathrm{~mm}\end{array}$ \\
\hline Wazer et al. [29] & 7 & 8 & $\mathrm{~N} / \mathrm{A}$ & All cases had positive margins \\
\hline Obedian \& Haffty [11] & 10 & $\begin{array}{l}\text { Pos: } 17 \\
\text { Close: } 2 \\
\text { Neg:2 }\end{array}$ & $\mathrm{N} / \mathrm{A}$ & $\begin{array}{l}\text { Close: }<2 \mathrm{~mm} \\
\text { Neg: } \geqslant 2 \mathrm{~mm}\end{array}$ \\
\hline
\end{tabular}

BCT: breast conservation therapy; N/A: not applicable; Pos: positive margins; Close: close margins; Neg: negative margins; LR: local recurrence.

\section{Factors to consider in assessing adequacy of excision}

\section{Margin orientation}

A close margin is of concern because it may be indicative of a significant residual tumor burden in the remaining breast tissue [12]. The anterior and posterior margins of the breast are anatomically limited by the skin and pectoralis fascia, respectively. Tumor that is close to these margins does not have the same implication for residual disease as tumor approaching a margin where residual breast parenchyma remains. In addition, these margins are often artificially distorted by compression devices used for specimen radiography. In one study of 220 cases, specimen handling and inking was completely controlled by the surgeon and compression was only permitted in an anterior-posterior direction. A close or positive margin in this compressed direction was never found to correlate with residual disease upon re-excision, while a single close non-compressed margin and multiple close non-compressed margins demonstrated residual disease in $35.7 \%$ and $47.3 \%$ of cases, respectively [13].

\section{Extent of tumor and margin width}

Residual tumor is present in approximately $50 \%$ of patients who undergo re-excision for close or positive 
margins [14]. Neuschatz et al. evaluated residual disease as a function of initial margin width and found that while 1-2 $\mathrm{mm}$ margins were associated with a $31 \%$ risk of residual tumor at re-excision, margins greater than $2 \mathrm{~mm}$ eliminated that risk completely, although there were only 10 patients with an initial margin of greater than $2 \mathrm{~mm}$ [12]. Data from the same group on the relationship between margin width and local recurrence rates confirmed the significance of this observation. At 12 years of follow-up, local recurrence rates for women 45 years of age and younger and women older than 45 with positive margins were $25 \%$ and $14 \%$, respectively. Excision to a negative margin width of $2-5 \mathrm{~mm}$ reduced local failure rates to $7 \%$ and $5 \%$, respectively [15]. Extent of margin positivity is a predictor of both local recurrence and residual disease at re-excision. Darvishian et al. identified residual tumor in 9 of 10 patients having $1 \mathrm{~cm}$ or more of tumor at the margin surface. In contrast, only 2 of 14 patients with margin involvement of less than $5 \mathrm{~mm}$ had residual tumor identified [16]. In the Joint Center for Radiotherapy at Harvard experience, extent of margin positivity correlated with rates of local failure [17]. Local recurrence was observed in $27 \%$ of women with extensively positive margins, $14 \%$ of those with focally positive margins, and $7 \%$ of women with close margins. Overall, this information suggests that while $2 \mathrm{~mm}$ margins of resection provide good local control for the majority of patients, the benefit of re-excision in patients with microscopic foci of tumor within $2 \mathrm{~mm}$ of a margin surface is likely to be small.

\section{Tumor histology}

Histologic tumor type has also been correlated with the likelihood of residual disease when patients with positive or unknown margins are re-excised. This correlation is most evident for tumors with an extensive intraductal component (EIC). Holland et al. have demonstrated that $40 \%$ of tumors with an EIC have residual tumor at a distance of $1 \mathrm{~cm}$ from the primary tumor compared to fewer than $5 \%$ of ductal carcinomas which lack an EIC [18]. Others have shown that the presence of an EIC is predictive of both local recurrence and a higher likelihood of finding residual tumor on re-excision for close or positive margins $[19,20]$. Invasive lobular histology is also associated with a higher likelihood of residual tumor in the breast when margins are positive or unknown when compared with invasive ductal carcinoma [21]. This is consistent with what is known about the infiltrative growth pattern of invasive lobular carcinomas.

\section{Patient age}

Younger patient age is associated with a higher risk of local recurrence after BCT in multiple randomized trials $[1,2,22]$. While the reason for this is not clear, it appears that a greater negative margin width may mitigate this effect. In the study of Neuschatz et al., a negative margin width of $2 \mathrm{~mm}$ or less in women less than 45 years of age was associated with a 12 year local failure rate of $19 \%$ which was reduced to $7 \%$ if margin width was between 2 and $5 \mathrm{~mm}$ [12]. The prospective randomized trial by Bartelink et al. examining the benefit of a boost dose of radiotherapy to the primary tumor site also confirmed the benefit of more aggressive local therapy to the primary tumor site in women age 40 years or less [22]. Thus, young patient age should not be viewed as an indication for mastectomy since excision to clearly negative margins and the use of a boost to the primary tumor site reduces rates of local failure significantly.

\section{Conclusion}

Local recurrence rates after BCT have decreased significantly since the initial adoption of BCT [23]. The reason for this decrease is multifactorial, and includes improvements in mammography, more detailed pathologic evaluation of specimen margins, and the widespread use of adjuvant systemic therapy. In a series of women treated in National Surgical Adjuvant Breast and Bowel Project (NSABP) trials in the 1990s who received adjuvant therapy, 10-year rates of local failure ranged from 3.5-6.5\% [24]. Despite these improvements in local control, attention has most likely remained focused on margin size because this is felt to be within physician control, although many factors beside the actual margin width influence the risk of local recurrence. The low incidence of local recurrence reported by the NSABP, using a definition of tumor cells not touching ink as a negative margin, indicates that dogmatic adherence to a defined margin width for all patients is inappropriate and is likely to result in unnecessary mastectomies. In evaluating the need for re-excision in patients with margin widths of less than $2 \mathrm{~mm}$ we consider patient age, tumor histology, which margin is approximated by tumor, and the extent of disease approaching the margin. These enable us to assess whether re-excision is likely to be beneficial when confined to the margin(s) approached by tumor. Re-excision limited to those margins involved by tumor has been shown to identify residual tumor with the same frequency as re-excision of the entire cavity [25], and results in the removal of far less breast tissue which helps to preserve cosmesis. In the future, genetic profiling may allow us to identify tumors with a locally aggressive phenotype that would benefit from wide local excision or even mastectomy. Without this information, decisions about the need for re-excision should continue to be made on a case by case basis. 


\section{References}

1. Fisher B, Bauer M, Margolese R, et al. Five-year results of a randomized clinical trial comparing total mastectomy and segmental mastectomy with or without radiation in the treatment of breast cancer. $N$ Engl $J$ Med 1985; 312: 665-673.

2. Veronesi U, Cascinelli N, Mariani L, et al. Twenty-year follow-up of a randomized study comparing breastconserving surgery with radical mastectomy for early breast cancer. N Engl J Med 2002; 347: 1227-1232.

3. Arriagada R, Le MG, Rochard F, Contesso G. Conservative treatment versus mastectomy in early breast cancer: patterns of failure with 15 years of follow-up data. Institut Gustave-Roussy Breast Cancer Group. J Clin Oncol 1996; 14: 1558-1564.

4. Poggi MM, Danforth DN, Sciuto LC, et al. Eighteen-year results in the treatment of early breast carcinoma with mastectomy versus breast conservation therapy: the National Cancer Institute Randomized Trial. Cancer 2003; 98: 697-702.

5. van Dongen JA, Voogd AC, Fentiman IS, et al. Long-term results of a randomized trial comparing breast-conserving therapy with mastectomy: European Organization for Research and Treatment of Cancer 10801 trial. J Natl Cancer Inst 2000; 92: 1143-1150.

6. Blichert-Toft M, Rose C, Andersen JA, et al. Danish randomized trial comparing breast conservation therapy with mastectomy: six years of life-table analysis. Danish Breast Cancer Cooperative Group. J Natl Cancer Inst Monogr 1992; Issue \#11: 19-25.

7. Fentiman IS. Long-term follow-up of the first breast conservation trial (Guy's Wide Excision Study). Eur J Cancer 1998; 34: S37-S38.

8. Fisher B, Jeong JH, Anderson S, Bryant J, Fisher ER, Wolmark N. Twenty-five-year follow-up of a randomized trial comparing radical mastectomy, total mastectomy, and total mastectomy followed by irradiation. $N$ Engl $J$ Med 2002; 347: 567-575.

9. Taghian A, Mohiuddin M, Jagsi R, Goldberg S, Ceilley E, Powell S. Current perceptions regarding surgical margin status after breast-conserving therapy: results of a survey. Ann Surg 2005; 241: 629-639.

10. Smitt MC, Nowels KW, Zdeblick MJ, et al. The importance of the lumpectomy surgical margin status in long-term results of breast conservation. Cancer 1995; 76: 259-267.

11. Obedian E, Haffty BG. Negative margin status improves local control in conservatively managed breast cancer patients. Cancer J Sci Am 2000; 6: 28-33.

12. Neuschatz AC, DiPetrillo T, Steinhoff $M$, et al. The value of breast lumpectomy margin assessment as a predictor of residual tumor burden in ductal carcinoma in situ of the breast. Cancer 2002; 94: 1917-1924.

13. Dooley WC, Parker J. Understanding the mechanisms creating false positive lumpectomy margins. Am J Surg 2005; 190: 606-608.

14. Luu HH, Otis CN, Reed Jr WP, Garb JL, Frank JL. The unsatisfactory margin in breast cancer surgery. Am J Surg 1999; 178: 362-366.

15. Neuschatz AC, DiPetrillo T, Safaii H, Price LL, SchmidtUllrich RK, Wazer DE. Long-term follow-up of a prospective policy of margin-directed radiation dose escalation in breast-conserving therapy. Cancer 2003; 97: 30-39.
16. Darvishian F, Hajdu SI, DeRisi DC. Significance of linear extent of breast carcinoma at surgical margin. Ann Surg Oncol 2003; 10: 48-51.

17. Gage I, Schnitt SJ, Nixon AJ, et al. Pathologic margin involvement and the risk of recurrence in patients treated with breast-conserving therapy. Cancer 1996; 78: 1921-1928.

18. Holland R, Connolly JL, Gelman R, et al. The presence of an extensive intraductal component following a limited excision correlates with prominent residual disease in the remainder of the breast. J Clin Oncol 1990; 8: 113-118.

19. Smitt MC, Nowels K, Carlson RW, Jeffrey SS. Predictors of reexcision findings and recurrence after breast conservation. Int J Radiat Oncol Biol Phys 2003; 57: 979-985.

20. Wazer DE, Schmidt-Ullrich RK, Schmid CH, et al. The value of breast lumpectomy margin assessment as a predictor of residual tumor burden. Int $J$ Radiat Oncol Biol Phys 1997; 38: 291-299.

21. Dillon MF, Hill AD, Quinn CM, McDermott EW, O'Higgins $\mathrm{N}$. A pathologic-assessment of adequate margin status in breast-conserving therapy. Ann Surg Oncol 2006; 13: 333-339.

22. Bartelink H, Horiot JC, Poortmans P, et al. Recurrence rates after treatment of breast cancer with standard radiotherapy with or without additional radiation. $N$ Engl J Med 2001; 345: 1378-1387.

23. Pass H, Vicini FA, Kestin LL, et al. Changes in management techniques and patterns of disease recurrence over time in patients with breast carcinoma treated with breast-conserving therapy at a single institution. Cancer 2004; 101: 713-720.

24. Wapnir I, Anderson S, Mamounas E, et al. Survival after IBTR in NSABP Node Negative Protocols B-13, B-14, B19, B-20 and B-23. In: Grunberg SM (Ed.). ASCO 41st Annual Meeting, Vol. 23. Orlando, FL: Lisa Greaves; 2005: 8s.

25. Gibson GR, Lesnikoski BA, Yoo J, Mott LA, Cady B, Barth Jr RJ. A comparison of ink-directed and traditional whole-cavity re-excision for breast lumpectomy specimens with positive margins. Ann Surg Oncol 2001; 8: 693-704.

26. Fisher B, Anderson S, Bryant J, et al. Twenty-year followup of a randomized trial comparing total mastectomy, lumpectomy, and lumpectomy plus irradiation for the treatment of invasive breast cancer. N Engl J Med 2002; 347: 1233-1241.

27. Freedman G, Fowble B, Hanlon A, et al. Patients with early stage invasive cancer with close or positive margins treated with conservative surgery and radiation have an increased risk of breast recurrence that is delayed by adjuvant systemic therapy. Int $J$ Radiat Oncol Biol Phys 1999; 44: 1005-1015.

28. Park CC, Mitsumori M, Nixon A, et al. Outcome at 8 years after breast-conserving surgery and radiation therapy for invasive breast cancer: influence of margin status and systemic therapy on local recurrence. $J$ Clin Oncol 2000; 18: 1668-1675.

29. Wazer DE, Jabro G, Ruthazer R, Schmid C, Safaii H, Schmidt-Ullrich RK. Extent of margin positivity as a predictor for local recurrence after breast conserving irradiation. Radiat Oncol Investig 1999; 7: 111-117. 